\title{
A COMISSÃO PASTORAL DA TERRA: HISTÓRIA E AMBIVALÊNCIA DA AÇÃO DA IGREJA CATÓLICA NO RIO GRANDE DO SUL
}

\author{
Cesar Goes \\ Universidade de Santa Cruz do Sul
}

\begin{abstract}
Resumo: Este artigo centra-se na análise das relações que deram forma à Comissão Pastoral da Terra (CPT) no Rio Grande do Sul, nos anos 1970 e 1980. Estuda essa formação através das rupturas provocadas pelas compreensões que os agentes expressaram sobre o sentidodo seu trabalhoparalelo à consolidação dos movimentos sociais no campo, em especial do Movimento dos Trabalhadores Rurais Sem-Terra (MST). Como resultado desse processo, estas concepçōes se redefinem, gerando ambivalências, tensões, rupturas e, enfim, apontando para alteraçôes de lugar e papel da CPT no contexto católico do Rio Grande do Sul e na compreensão que os agentes elaboram a respeito de sua ação.
\end{abstract}

Palavras-chaves: agentes religiosos, CPT, MST, pastoral.

Keywords: CPT, MST, pastoral care, religious agents.

O presente trabalho ${ }^{1}$ parte da análise do papel que agentes religiososque atuaram na Igreja Católica do Rio Grande do Sul desempenharam na forma-

\footnotetext{
${ }^{1}$ Este artigo tem como base a discussão proposta pelo autor para defesa de dissertação de mestrado pelo Programa de Pós-Graduação em Sociologia na Universidade Federal do Rio Grande do Sul (UFRGS) em dezembro de 1997. De lá para cá, a reflexão está mediada por um conjunto de incursões na forma de assessorias que o autor realizou neste meio. Além do ambiente receptivo da CPT, o autor agradece publicamente o trabalho do prof. Dr. Ivaldo Gehlen, atual orientador de doutoramento, bem como as sugestôes dos professores Dr. Carlos Steil e Dr. José Vicente Tavares quando da oportunidade da defesa, esperando tê-las incorporado nesta elaboração. Agradece ainda a permanente troca de idéias e o entusiasmo mantido com o professor Dr. Zander Navarro, no entanto alerta que as opiniōes emitidas são apenas de sua estrita responsabilidade.
} 
ção e na consolidação dos movimentos sociais nas décadas de 1970 e 1980. Privilegiam-se para tanto duas das lutas que mais se destacaram na questão da terra no estado nesse período: os acampamentos da Encruzilhada Natalino e o da fazenda Anoni. Investiga-se como este envolvimento alterou a representação dos agentes religiosos quanto aos princípiosque orientaram a continuidade da Comissão Pastoral da Terra (CPT) no Rio Grande do Sul, através da relação estabelecida entre os agentes religiosos e os trabalhadores rurais.

A lógica deste percurso compreensivo apóia-se na indagação de Doimo (1985), para quem a motivação individual e a estrutura são ambos responsáveis para a compreensão dos fenômenos sociais:

[...] como entender a instauração desse novo tempo "popular", senão através do resgateda complexainteração seletiva que se estabeleceu entre determinadas instituições, formações e tradiçôes no incremento à participação movimentalista? (Doimo, 1985, p. 73).

Ao cercar essas duas lutas e indicar neste campo de relações os efeitos que incidiram sobre a definição da ação da CPT, pergunta-se sobre as repercussóes institucionais, apresentando a CPT como mediadora de relações, que, por um lado, influenciou a institucionalização da luta pela terra em torno da organização do Movimento dos Trabalhadores Rurais SemTerra (MST) no Rio Grande do Sul e, por outro, apontou questóes para a prática pastoral cujas dimensões desafiaram o ritmo e o formato das decisões institucionais da Igreja.

Eleger a Encruzilhada Natalino e a fazenda Anoni como cenários privilegiados para demonstrar este processo, significou aprofundar de modo cronológico e comparativo os fatos que fizeram o roteiro daquelas relações.

$\mathrm{Na}$ Encruzilhada Natalino, acampamento que marcou a retomada da luta pela terra no Rio Grande do Sul (Marcon, 1989) as relações eram mais homogêneas e verticalizadas, tendo o agente religioso uma posição privilegiada na medida em que havia menos lideranças leigas, e estas com pouca experiência no cenário da luta.

$\mathrm{Na}$ fazenda Anoni havia uma maior pluralidade de sujeitos, inclusive outras entidades religiosas e entidades da sociedade civil, abrindo a possibi- 
lidade do surgimento de um leque de estratégias mais amplas, com vistas ao alcance das metas.

Essas diferentes possibilidades se constituíram em práticas de luta pela terra que reordenaram as relações entre os agentes religiosos aí envolvidos e as lideranças de agricultores, gerando um quadro de rupturas. Estas aconteceram em dois níveis:

a) internos à própria CPT, em que agentes mais identificados com estas novas estratégias assumiram cargos de coordenação e representação da CPT no estado;

b) externos, em que agentes mais antigos se afastam das esferas das decisõesdessas lutas, uma vez que discordavam das direçōesestabelecidas para a continuidade das mesmas.

Interessa discutir o quanto essas rupturas estiveram vinculadas à crescente autonomia dos movimentos em relação à influência dos agentes da CPT, levando-a a um papel que ela mesma define como contribuição ao que quer como causa dos trabalhadores e condição de continuidade como uma entidade de serviço e apoio aos movimentos.

Nas lutas aqui abordadas e nos desdobramentos dessas relações como transformadoras do perfil da CPT, o conjunto de sujeitos envolvido pode ser assim expresso:

[...] extensas redes sociais [que] desenharam, entre os anos 1975-1990, um expressivo campo ético-políticoà base de movimentos reivindicativos de açãodireta, autoreconhecidos como movimento popular, mediante apoio de significativos setores da Igreja Católica, do ecumenismo, de segmentos da academia científica e grupamentos de esquerda, estes quase sempre inseridos na chamadas ONG's, organizações não governamentais. É profundamente intrigante verificar, no entanto, que tanto em relação aos "novos movimentos sociais" como em relação ao movimento popular, tudo isso seja comumente suprimido dos cenários dos conflitos, em nome da suposta organização espontânea. (Doimo, 1995, p. 67). 
Para situar o debate, adota-se uma periodização da trajetória da CPT de acordo com a sua relação nos contextos da luta pela terra no estado.

As delimitações dos períodos apresentados são recursos para se compreender melhor a trajetória da CPT.

\section{A CRUZ DA ENCRUZILHADA NATALINO}

O acampamento da Encruzilhada Natalino foi um marco na retomada da luta pela terra no Rio Grande do Sul. Ao lado de outros movimentos que alcançaram uma repercussão ampla no início da década de 1980, o acampamento da Encruzilhada Natalino se destacou, quer pela sua duração (três anos até alcançar uma solução final), quer pelo grau de enfrentamento que esta luta atingiu, em particular com o aparato militar do Estado.

Martins (1984) caracteriza esse período:

Os agentes do poder tradicional estão sendo cooptados pelos executores e interventores locais da política de centralização e de federalização, para conter e desmoralizar a força e a ação, na construção da expressão política dos trabalhadores do campo, do sindicato, do partido e, até da Igreja. Um produto característico desse processo e desse impacto político é a utilização do oficial militar para preencher o lugar do chefe político tradicional ou para ressuscitálo. Tem esse papel a figura ubíqua do "major Curió", um tenente-coronel do Exército, a serviço do Conselho de Segurança Nacional, que combateu a guerrilha do Araguaia, foi ferido por uma guerrilheira, aliciou camponeses e deu-lhe terras. Ele tem estado em vários dos conflitos pela terra ultimamente: no baixo Araguaia, no norte de Goiás, em Alagamar (Paraíba), em Ronda Alta (Rio Grande do Sul). Ele estabelece no campo as mesmas relações patrimoniais e tradicionais dos velhos coronéis sertanejos, isolando antes os camponeses de contatos com diferentes setores da sociedade civil, como fez nos núcleos das estradas operacionais OP-2 e OP-3, no garimpo de Serra Pelada, em Ronda Alta e, de certo modo, em Alagamar. Sem dúvida, uma grande volta na história do Exército brasileiro, tradicional adversário dos coronéis do sertão. (Martins, 1984, p. 60). 
Nesse quadro, o autor aponta a expansão da fronteira agrícola como um aspecto que se tornou estratégico para a continuidade do regime militar, uma vez que este aumentava muito a sua área de influência. Contraditoriamente, estabelece-se um confronto político, na medida em que tornava "mais nítido e significativo o confronto entre capitalista e o estado, de um lado, e camponeses de outro" (Martins, 1984, p. 60-61).

Este era o cenário sob o qual se desenrolava o episódio, incluindo a intervenção militar. Os sujeitos eram diversos: agricultores sem terra, agentes religiosos, entidades de apoio da sociedade civil, parlamentares, secretários de estado e chefes do poder executivo.

Já há uma bibliografia que apóia o estudo desse conflito. Apesar de os modelos de análise se distinguirem bastante, Marcon (1989) privilegia a apresentação do acontecimento e Costella (1992) estabelece uma comparação da Encruzilhada Natalino com o MASTER ${ }^{2}$ no Rio Grande do Sul; ${ }^{3}$ são trabalhos que resgatam os fatos e personagens envolvidos, além de situarem, sob o aspecto institucional, o papel da Igreja no episódio.

Gaiger (1987) veio completar o quadro referencial dos trabalhos a respeito da Encruzilhada Natalino, sobre os quais se apóia este artigo, por ter privilegiado na análise a ação dos agentes religiosos no acontecimento.

Em comum nos trabalhos estava o fato de terem demonstrado a oposição mais forte entre a Igreja e a ditadura militar, bem como os momentos onde agentes religiosos também apresentavam divergências entre si, uma vez que não compartilhavam da mesma leitura a respeito das prioridades do trabalho pastoral.

2 O Movimento de Agricultores Sem Terra (MASTER) foi uma formação política dirigida pelo então PTB na década de 1950 e obteve um peso político considerável no cenário político do Rio Grande do Sul no início das agitações em prol da reforma agrária. Foi duramente reprimido pelo governo militar. Para maiores informações recomenda-se uma leitura na dissertação de Eckerdt (1984).

3 A esse respeito, o trabalho de Eckert (1984) constitui-se em referência obrigatória, ao qual ambos os trabalhos se remetem quando tratam do MASTER. 
A periodização do episódio também é comum nos trabalhos, uma vez que tanto Marcon quanto Costella dividem-na em quatro fases, a saber:

A trajetória do acampamento, desde a sua constituição em 1980 até o assentamento definitivo em 1983, pode ser dividida em quatro fases distintas: a primeira, que vai da gestação do acampamento até o final do mês de julho de 1981; uma segunda, que abrange o período da intervenção militar-federal durante o mês de agosto de 1981; a terceira, que vai da saída dos interventores até o assentamento provisório em Nova Ronda Alta, em março de 1982, e a quarta que vai do assentamento provisório em Nova Ronda Alta ao assentamento definitivo em outubro de 1983. (Marcon, 1989, f. 66).

Há um aspecto que une os dois trabalhos e que os dados aqui apresentados permitem questionar, o de que o acampamento iniciou mais ou menos espontaneamente, a partir de alguns agricultores remanescentes dos conflitos das reservas indígenas de Nonoai:

A formação do acampamento não resultou de uma prévia articulação dos acampados; foi fruto, antes de mais nada, da premência das condições materiais e da ausência absoluta de perspectivas das famílias de agriaultores sem-terra e minifundiários. As primeiras a acamparem nele eram provenientes da reserva de Nonoai e não haviam sido contempladas nos assentamentos nas Granjas Macali e Brilhante. Sem altemativas, elas foram se estabelecendo ao longo da rodovia, abrigadas em barracos de plástico ou de capim, buscando, com isso, chamar a atenção do governo para o problema ainda se soluçáa. (Marcon, 1989, f. 66).

Esses primeiros episódios estão sistematizados em Gehlen (1983), e oferecem elementos que permitem mapear a diversidade de contribuições e apoio para estas primeiras manifestações, e que enfrentam a visão de espontaneísmo.

No discurso dos agentes surgiram elementos para questionar essa espontaneidade e compreender o surgimento do acampamento como uma síntese entre a realidade da vida social apresentada pelos autores acima e o trabalho de agentes mediadores, religiosos ou não, e não necessariamente oriundos do local dos acontecimentos. 
Quanto aos agentes religiosos, foi por meio das instâncias e das atividades formais da Igreja, como encontros, cartas e comunicaçóes, que muitos se envolveram com esse tipo de processo. $\mathrm{O}$ primeiro depoimento foi do então coordenador da CPT no período, padre João Bosco Schio:

Realizaram-se muitas atividades e mobilizações, indo-se até as autoridades. Sem maiores soluções, em março de 1981, alguns sentiram que a única saída para conseguirem terra era acampar. Animaram-se para tanto em vista do sucesso que obtiveram os colonos que acamparam e invadiram as fazendas Brilhante e Macali, pertencentes ao Governo. O local escolhido para acampar era justamente em frente às mesmas glebas invadidas, pois, além de contarem com a ajuda dos colonos vitoriosos, aí perto havia outra área do Governo desocupada: a Fazenda Anoni. Isto tudo foi decidido por eles, como diziam: "Premidos pela necessidade e animados pela fé e pela esperançă". Como se vê a Igreja esteve presente desde o início, tanto a modernizada como a comprometida, oferecendo o espaço de reflexão aos grupos, apoiando suas mobilizações e ajudando a descobrir novos caminhos à luz da fé. Serviram não só os grupos, mas também as celebrações, estudos, etc. (Schio, 1985, p. 199-200).

A história do padre Arnildo Fritzen, ${ }^{4}$ durante esse período, constituise num depoimento central para compreender melhor esse acontecimento. Há nele as características da liderança carismática. Sua trajetória dá conta de situações difíceis quanto à sua rotina no trabalho pastoral, e estas experiências lhe conferiram um conhecimento da mobilidade da instituição da qual fazia parte, podendo the garantir uma sabedoria particular e refinada a respeito da mesma.

Isso explica sua facilidade para estabelecer estratégias de negociaçóes antes e durante todo o período do acampamento, e não foi possível negar a sua centralidade no episódio, revertendo-se em seu favor vários aspectos,

${ }^{4}$ As referências ao padre Arnildo Fritzen foram apoiadas em transcrição de entrevista realizada por Miguel Carter (1994), então doutorando da Columbia University, que interagiu com o autor durante trabalho de campo no Rio Grande do Sul, para o qual disponibilizou as gravações. 
uma vez que, ao contrário do que é comum acontecer nesses episódios, onde a Igreja transfere o sacerdote de paróquia, ${ }^{5}$ esta possibilidade configurou-se apenas como ameaça, não chegando a se concretizar.

Outro indicador importante da presença dos agentes religiosos nessa trajetória foram as sucessivas polêmicas durante o episódio envolvendo autoridades eclesiais, meios de comunicação, representantes governamentais, em torno das ações dos mesmos, na Encruzilhada Natalino.

A participação de religiosas, no mesmo nível de intervenção, ainda está por ser trabalhada com mais acuidade. As religiosas Aurélia, Lurdes e Isabel permaneceramaté que se permitisse,juntamente com o padre Arnildo, na assistência aos acampados.

Esse trabalho constituía-se numa perspectiva de prática pastoral pouco desenvolvida no estado, mais própria de realidades do Norte brasileiro e é de lá que o padre Arnildo trouxe as primeiras reflexões a respeito do assunto:

Quando terminou o ano letivo eu decidi ir para lá. Disse então que ia ficar fora um mês para visitar meus parentes no Paraná e na verdade eu fui para Goiás, pra conhecer a experiência de trabalho da Diocese de Goiás Velho e poder me encontrar [...], e aí eu devo dizer com toda a alegria e toda a franqueza que lá encontrei um trabalho, uma diocese com uma opção clara de trabalho com os pobres, com uma metodologia de trabalho de libertação [...] lá estavam D. Tomás Balduíno, o Ivo Polet to que era coordenador de pastoral. Um outro que me impressionou muito era um monge beneditino, o Marcelo de Barros [...] Acompanhei muitas perseguiçóes de lavradores, tinha lavradores presos, fazia passeata de solidariedade, e lá eu tinha me

5 É notável tal situação, uma vez que esse recurso é usado em muitos casos considerados de “in transigên cia” por parte de u m sacerdote que está lotad o em paróquia. As transferências de sacerdotes de paróquias é um procedimento comum na Igreja Católica e há uma rotina para tal, anualmente, gerando expectativa nos meios eclesiais. Como é um procedimento centralizado em torno do bispo local, este pode utilizá-lo como recurso para resolução de conflitos locais, ficando muitas vezes difícil comprovar tal atitude, uma vez que ela se reveste de um caráter formal e rotineiro.

Debates do NER, Porto Alegre, Ano 5, N. 5, P. 105-141, junho 2004 
decidido, só volto para casa para comunicar que eu vou ficar nessa diocese. (Carter, 1994, p. 6).

Essa prática anterior, vivenciada no Norte, fora aqui retomada no seu trabalho. e era o cenário onde a atividade pastoral tomava corpo na paróquia. Generalizando, esses procedimentos são características de açóes que formam as CEB's. Estas se constituíram em embriōes de ap rendizado para mobilizações cada vez de maior abrangência, seja territorial, seja no número de pessoas envolvidas.

Macali e Brilhante (Gehlen, 1983) são nomes de áreas de ocupações precursoras nesse aprendizado e proporcionaram a todos os que nelas se envolveram uma visão dos conflitos que emergiram nesse tipo de questão, em especial a respeito das possibilidades de alianças em torno desses cenários. A equipe da paróquia acompanhava esses movimentos. Quando o Estado dispersava as famílias a partir de um cadastramento em que prometia chamá-las em breve, juntamente com outros agentes a paróquia os reunia em busca de alternativas:

No começo de 79, algumas famílias vêm para cá e a gente acolhe eles aqui na casa e a gente...com eles nós começamos a fazer leitura da Bíblia. Lemos a história do Evangelho e aí é que começa a nascer entre eles aquela história [...] essa é a nossa história. Estamos no meio da escravidão, e temos que sair da escravidão para uma terra... Eram mais ou menos umas 40 pessoas, dormiam no chão...Isso para o pessoal da cidade foi o maior desaforo, e então é que entra o João Pedro nessa história. Em março [de] 1979, ele vem para cá com outros colegas e então começamos a conversar. Ele veio ver como estava a situação e o que podia se fazer e nós montamos um plano estratégico, eles foram para Planalto, Nonoai e Três Palmeiras, onde fui me encontrar com eles à noite. Foram três assembléias diferentes para discutir quem era

\footnotetext{
${ }^{6}$ Por compreensões diferentes a respeito do trabalho que realizava, o padre Arnildo foi afastado do acompanhamento de seminaristas e colocado, usando uma expressão sua, du rante um período em "deserto", em um seminário nessa cidade.
} 
expulso. Planalto e Nonoai foi no campo mesmo e Três Palmeiras, de noite, foi num clube, emprestado. Bom, e por aí começou a se desencadear essa organização com esse pessoal para reivindicar diante do governador e depois como ele prometeu e não cumpriu o pessoal ir organizar a Macali, a Brilhante, então começa por aí, no começo de 79 , a organização disso. ${ }^{7}$ (Carter, 1994, p. 7-8).

A ação pastoral tomava a forma de um acompanhamento quotidiano, onde o padre participava ativamente, com outros agentes externos, das decisões em torno de estratégias de continuidade, como protestos, negociaçôes com a polícia militar e outros que entendessem necessários. De uma atitude retórica comum aos partidos de esquerda de então (Martins, 1981, 1984), o acompanhamentodessas lutas impunha posturas menos discursivas e passava a exigir destes agentes uma reflexão a respeito de situações concretas, alternativas de sobrevivência para um grupo bem localizado, presente, e, nesse caso, dentro da casa do padre, o que no Sul era novidade.

O acampamento da Encruzilhada Natalino (1981 a 1983), iniciado há quase dois anos desses episódios relatados acima, foi o resultado, na visão dos agentes religiosos que o acompanharam, de um trabalho de continuidade na região.

\footnotetext{
7 Além do fato de escolher um grupo desse tamanho na casa paroquial, contra a vontade do próprio conselho da paróquia, segundo o depoimento, essa passagem aponta a participação de João Pedro Stédile, então funcionário da Secretaria da Agricultura, que passa a ter um papel cada vez mais central nesses trabalhos. No início como técnico do governo, depois como assessor da CPT, onde se manterá até o fim da luta da Encruzilhada Natal in o. A partir de então, envolve-se na orga nização do "Movimento dos Sem Terras" (denominação comumente utilizada na fase inicial do MST), articulando lutas dispersas nos estados do Sul, mas que possuíam uma coisa em comum: em todas havia agentes da CPT, religiosos ou leigos como ele, que facilitavam imensamente o intercâmbio entre esses trabalhadores. É essa rede que irá proporcionar a realização, posteriormente, do primeiro encontro de agricultores sem terra da Região Sul, em Cascavel, no Paraná, em 1984. Esse encontro pode ser considerado o marco para a organização nacional que se apresenta no I Congresso Nacional de Trabalhadores Rurais Sem-Terra, em Curitiba, no Paraná, em 1985 (Navarro, 1996).
} 
Da ação dos agentes religiosos em torno dos primeiros meses do acampamento pode-se afirmar que a influência está na própria organização do acampamento. Grupos de trabalho e grupos de discussóes organizados por proximidade dos barracos, e, na medida em que o acampamento aumentava, os recém-chegados eram convidados a integrar-se nessa dinâmica. Era na organização desse quotidiano, na interação entre o trabalho dos agentes religiosos e dos agricultores acampados, que emergiu um símbolo que se tornou o cartão de apresentação dessa luta: a Cruz de Natalino.

Nos primeiros anos do movimento sem-terra, a cruz seria assumida como o seu símbolo. Na medida em que a luta crescia, primeiro em torno do acampamento e depois em torno do Movimento Sem-Terra, miniaturas eram feitas pelos agricultores e entregues como lembrança, como prêmio de reconhecimento aos "companheiros de luta". Em certa medida, a troca de símbolo do Movimento Sem-Terra, da cruz, que nunca foi assumida oficialmente, para a bandeira que era anunciada como símbolo oficial, também é a história do distanciamento gradativo que agentes religiosos, como o padre Arnildo, vão tendo das esferas de decisão.

A cruz era peculiar e trazia para o acampamento a simbologia que acompanha as manifestaçôes religiosas e que estabelece, nas lutas sociais, os refe renciais religios os que conferiram possibilidade de repe rcussão institucional quando do sentido ao símbolo. A Cruz de Natalino multiplicou-se, além de várias que, no decorrer do tempo dessas lutas, foram reconhecidas como as principais e desde o início assumidas como símbolos da luta. Essa escolha reflete o grau de interação dos agentes religiosos com a estruturação do acampamento.

Ainda havia mais um ingrediente nessa simbologia. Quando da morte da primeira criança no acampamento, foi enrolado à cruz um lençol branco, simbolizando um luto, expressado na fala dos acampados e dos agentes como sinal de esperança. A cada morte eram acrescidos panos brancos. Seis anos depois, quando a cruz foi resgatada (reconstruída) como símbolo do acampamento da fazenda Anoni, a prática de simbolizar as mortes continuava em torno dela. 
$\mathrm{Na}$ intervenção militar no acampamento, que durou um mês, a Cruz de Natalino como ficou conhecida então, passou a ser o símbolo da resistência frente à intervenção:

No dia 30 de julho, no entanto, sem consulta alguma, o major Curió instalouse no acampamento, que ficou sob sua responsabilidade e de sua equipe de assessores. Ele se apresentou "em nome da presidência da República" e destacou que tinha como objetivo solucionar o impasse entre governo e colonos num prazo de 15 dias. A partir de então, o Acampamento Natalino foi considerado área de Segurança Nacional. (Marcon, 1989, f. 110-111).

Marcon (1989) desenvolveu a reflexão com base nos motivos pelos quais o Estado, com a intervenção, configurava o acampamento como área de segurança nacional e das estratégias adotadas para que os agricultores assumissem a proposta governamental: ir para colonizaçōes no Mato Grosso, Bahia, Acre ou Roraima. Tanto este autor quanto Costella (1992) afirmaram ser esse período de 30 dias, em que o coronel Curió manteve a intervenção no acampamento, um período definidor de novas estratégias. A primeira foi amadurecer uma forma de dialogar com diferentes posicionamentos internos da hierarquia.

Em função do confronto que ali se estabeleceu, o bispo da diocese, D. Cláudio Colling, já havia se posicionado, pois estivera no acampamento como porta-voz do governo para propostas de emprego em estações experimentais e foi solicitado a se retirar pelos próprios agricultores:

[...] mas quando ele disse assim: "Vocês, pai de família, hoje à noite, quando estiverem com a cabeça nos travesseiros, pensem bem no que vocês estão fazendo aqui. Fazer estas crianças sofrer assim. Pensem bem e voltem para casa", e aí um gritou lá do fundo: "Precisava ter travesseiro, senhor bispo". (Carter, 1994, p. 20).

O arcebispo de Porto Alegre, D. Vicente Scherer, pouco antes da intervenção fez publicar um pronunciamento deslegitimando a ação dos agentes religiosos e da CPT junto aos acampados. Estes mesmos religiosos 
acabaram por ocupar parte da atenção da mídia e dos outros grupos envolvidos nas negociações.

Se durante os 30 dias não se conseguiu muito em relação ao seu afastamento, depois da retirada da intervenção militar o padre Arnildo foi afastado das atividades junto aos agricultores em troca da garantia dos militares, para o episcopado gaúcho, do seu não enquadramento na Lei de Segurança Nacional; outra irmã, de nome Aurélia, para não ser enquadrada na Lei dos Estrangeiros, foi transferida pela sua congregação ao seu país de origem.

Durante a intervenção, ocorreu uma reunião dos bispos do Rio Grande do Sul que foi definidora para impulsionar um movimento interno na Igreja gaúcha que somente chegou ao final quando a própria Igreja assumiu o desfecho do acampamento, quase seis meses depois. Intitulada Reflexões Pastorais sobre o Agricultor sem Terra, a carta foi o posicionamento do conjunto do episcopado gaúcho em prol da luta dos agricultores acampados, e limitava-se à interpretação da expectativa da Igreja:

Talvez valesse a pena aprofundar a experiência comunitária, vivida no acampamento, para a prática de um sistema de produção cooperativa, expressão do autêntico cooperativismo. Neste caso bastariam extensões bem menores de terra e menos implementos agrícolas, mas com mais segurança para as famílias, podendo diversificar melhor os produtos da terra, com garantia de melhores preços. (Rev. Renovação, n. 148, 1981, p. 2).

No contexto de absoluto desastre que se revelou a intervenção no acampamento (Navarro, 1996, p 92), um dia antes da reunião o coronel Curió proibiu a entrada no acampamento de qualquer agente religioso (Marcon, 1989, f. 134). Isso soou como confronto para um episcopado, que até então se pautara por posições de diálogo com o governo. Sabe-se que anteriormente a essa reunião, um bispo conseguiu entrar sozinho no acampamento ainda durante o cerco militar, dirigindo ele mesmo um pequeno caminhão levando roupas e alimentos e, conversando em separado com o coronel Curió e com a coordenação dos agricultores, saiu de lá convicto da necessidade de uma mediação da Igreja. Oficialmente, a saída do Exército aconteceria somente com negociação ou com o fim do acampamento. Houve 
uma negociação, a partir daí, para a alternativa ao acampamento. O bispo fora sozinho levar comida e roupa aos acampados.

A carta ainda apresentava alternativas que foram viabilizadas na forma de um projeto implementado pela Cáritas do Regional Sul III (RS) seis meses depois, e solicitava:

1) crédito fundiário para adquirir aqui mesmo suas próprias terras; se havia crédito para o supérfluo, com maior razão deveria haver para o necessário;

2) redução do módulo rural para que, na fazenda Anoni, pudessem ser assentadas mais famílias do que o previsto.

Esse posicionamento serviu como sinal para que imediatamente os diversos setores da Igreja, simpáticos à luta dos agricultores, iniciassem um processo de mobilização a fim de garantir a permanência do acampamento depois da saída do Curió e a continuidade daquela luta.

O saldo da intervenção não foi, por certo, apenas positivo na ótica da permanência dos agricultores no estado, uma vez que cerca de 160 famílias aceitaram as propostas de colonização no Mato Grosso e na Bahia, e, ainda durante a intervenção militar, iniciou-se a transferência das mesmas. Do acampamento da Encruzilhada eram transferidos para outro acampamento, montado pelo exército, que levou o nome de Quero-Quero, e deste então partiam para as colonizaçôes. ${ }^{8}$

No intuito de garantir esta continuidade, e na intenção de demonstrar solidariedade aos agricultores que ficaram, agentes religiosos promoveram a maior concentração de apoio da Igreja aos agricultores até aquele momento: mais de 300 religiosos se concentraram no acampamento, em ato ecumênico. $\mathrm{O}$ ato foi também em desagravo às acusaçôes feitas pelo coronel Curió no documento Aos Colonos de Encruzilhada Natalino (e ao Povo

\footnotetext{
${ }^{8}$ No trabalho de Marcon, há preciosos depoimentos de agricultores que construíram suas justificativas para essa atitude. A marca dos depoimentos é, sem sombra de dúvida, a resignação frente à falta de perspectivas para a situação.
} 
Gaúcho) - Comunicado ñ 3. O comunicado fez um balanço do ponto de vista da assim chamada Coordenadoriado Acampamentodo Natalino,autoreferência do coronel Curió ao seu cerco, e atacou duramente o trabalho da paróquia de Ronda Alta e dos grupos que durante o tempo de sua permanência no acampamento lhe fizeram oposição:

O objetivo está, portanto, bem claro. A CPT quer transformar o Acampamento do Natalino num foco que simbolize o início de uma mudança social, que desrespeite o direito de propriedade, garantido pela Constituição (por ser um dos fundamentos da sociedade brasileira) e de leis que regulem a posse e uso da terra. Para esse fim Ronda Alta se insere num amplo complexo, dentro do qual se instigam os agricultores ese promovem invasóes de terras em várias áreas do País. (Marcon, 1989, f. 213).

O comunicado foi um ataque frontal ao trabalho da Igreja na Encruzilhada Natalino. Além das organizações, atacou nominalmente agentes e autoridades eclesiáticas que de alguma forma se manifestaram durante o período que lá esteve, entre os quais D. Thomás Balduíno, bispo de Goiás Velho (GO), vice-presidente do Conselho Indigenista Missionário (CIMI), e D. Moacir Grechi, bispo da diocese do Acre-Perus.

O texto também resgata as declarações de D. Vicente, aqui já mencionadas, além de usar do mesmo recurso de linguagem dos textos da Igreja, uma vez que cita textos bíblicos: Mat 7,15; Mar 15,8-9; Mat 23,3, para referendar as acusações acima. De alguma forma há a mediação também aqui de uma leitura religiosa, seja por intermédio de agentes que colaboram com a intervenção militar, seja pela familiaridade da equipe do coronel Curió com esse tipo de confronto.A CPT foi o alvo principal dessa investida, uma vez que as ações de repressão por parte do governo federal, com o fim da intervenção militar, continuaram tendo como centro os religiosos envolvidos na questão.

Outro documento que envolveu essa questão foi a publicação de um artigo de D. Vicente Scherer, intitulado Terras da Igreja (Scherer, 1981). Se em si o texto era uma prestação de contas para a sociedade, pensar nele trabalhado por quem tratou de descredenciar o trabalho da CPT como 
vinculado à Igreja no Rio Grande do Sul só se justificaria pelo ataque frontal sofrido pela instituição.

E foi a partir desses acontecimentos que a situação se encaminhou, desde setembro, para uma alternativa onde se acalmava a tensão do acampamento, mas que, uma vez transformado em um símbolo inclusive internacional, ${ }^{9}$ deveria haver também um significado de vitória. O número de agricultores que cederam às propostas do coronel Curió permanecia como sinal do desgaste do acampamento. E neste sentido amadureceu a proposta que revelou como, em determinadas situações, a Igreja emprestou muito mais que um fôlego a uma luta popular (Doimo, 1995, p. 149).

Esse acompanhamento, no episódio do acampamento da Encruzilhada Natalino, realizou-se até a decisão definitiva que determinou a sua transferência, em março de 1982, para uma área de terras comprada pela Igreja:

A idéia original, na verdade, é de um próprio bispo, D. Jaime Chemello, que numa conversa com o irmão Antônio Cechim, falando sobre a Encruzilhada, ele levantou que a Igreja deveria dar um sinal profético e arrumar um pedaço de terra para retirar este pessoal da estrada, e coisa e tal. Essa idéia foi trazida para a reunião dos religiosos dia 8 de setembro e discutida, e foi mais ou menos uma idéia meio consensual que isso poderia ser proposto, para a comissão dos acampados, e aí levantamos para a reunião das liderança e levantamos essa idéia. Mas assim, não no sentido de que a Igreja vai ser boazinha, vai dar pra vocês, mas levantamos que diante dos problemas diários, da miséria da beira de estrada, se fosse questionar os bispos e pastores e exigir deles, nessa hora tão difícil pra poder no mínimo, usando o argumento do calor, do tempo, etc., ver um lugar para que eles pudessem se reorganizar e continuar a lutar pela terra. Se colocou assim para as lideranças e foi discutida nos grupos como era de costume e veio para a plenária, e essa idéia foi amadurecida e foi cheia de riqueza e contribuição, na assembléia foi aprovada e foi até escolhida uma comissão que fosse propor isso aos bispos e pastor. A comissão entre outros tinha o Antoninho, o Calegari, era um grupo assim e

\footnotetext{
9 Ainda estão por ser trabalhadas as correspondências de solidariedade ao acampamento. São centenas reunidas e, até anos atrás, permaneciam sob a guarda do Centro de Assessoria Multiprofissional (CAMP), uma ONG em Porto Alegre.
} 
nesse grupo foi o Antônio Cechim e aí se escolheu os bispo chaves que pudessem levar essa idéia pra frente, na época se escolheu D. Sinésio, na época de Novo Hamburgo,o bispo de Pelotas, D. Ivo de Santa Maria e D. Edmundo também foi procurado e D. Orlando também. (Carter, 1994, p. 29).

A negociação se estendeu até fevereiro, quando os bispos reunidos em Itaici, discutiram, em fórum somente dos bispos do Rio Grande do Sul, a proposta de compra de uma área para a transferência dos agricultores. A reunião aconteceu em Itaici pela urgência e pelo fato de não haver outro momento onde estivessem todos reunidos. Com a decisão da compra acertou-se também uma série de coletas nas missas no Rio Grande do Sul em prol da mobilização para a compra da área, além de mobilizar as organizações de apoio financeiro para obras sociais da Igreja na Europa. A coleta se estendeu durante quase todo o primeiro semestre de 1982, envolvendo inclusive a Campanha da Fraternidade daquele ano.

Na publicação oficial da CNBB, Revista Renovação, a partir de março de 1982 encontrou-se uma série de relatos a respeito das mobilizações das dioceses. $\mathrm{O}$ acompanhamento da questão foi assim sistematizado:

Fatos Recentes Sobre Nova Ronda Alta - que é uma primeira prestação de contas da coordenação: Por ocasião da Romaria da Terra, promovida pela CPT no local do acampamento de Encruzilhada natalino, e que se realizou no dia 23/02 p. p. , os bispos presentes à Romaria comunicaram aos colonos acampados e ao povo presente à Romaria sua decisão de apoiar o projeto de um novo acampamento em terra particular, comprometendo-se em organizar uma campanha para angariar fundos para a aquisição de uma gleba, destinada ao reassentamento provisório dos colonos. Pediram apenas que se elaborasse um projeto mostrando a viabilidade e os procedimentos concretos para esse assentamento provisório dos colonos. Sugeriram ainda que além do apoio da CPT e da Cáritas, e de outros organismos já engajados, se procurasse o apoio técnico do Núcleo de Cooperativismo do Centro de Documentação e Pesquisa da Universidade do Vale do Rio dos Sinos (UNISINOS), de São Leopodo e da Faculdade de Agronomia da Universidade de Passo Fundo. (Rev. Renovação, n. 154, p. 14). 
Outros projetos foram elencados:

- Projeto da Campanha de Apoio - onde se definiram as responsabilidades, com o centro do trabalho encaminhado pela Cáritas Regionale como seria a sistemática de venda de bônus, que correspondia a parcelas do valor de cada hectare da terra adquirida.

- Campanha Nova Ronda Alta - relatório de como a campanha aconteceria em cada diocese, com informações de Caxias do Sul, Cruz Alta, Erexim, Novo Hamburgo,Passo Fundo,Porto Alegre, Rio Grande, Santa Cruz do Sul, Santa Maria, Santo Ângelo (Rev. Renovação, n. 159, 1982, p. 19-28).

Esta é uma amostra de como a Igreja se movimentou em função da garantia dos recursos adiantados para a aquisição da terra. Esta, por sua vez, ficou em concessão de uso para os agricultores que ali permaneceram a partir de 1984, quando saíram as últimas famílias para os assentamentos definitivos, até o término do pagamento.

Os dois anos subseqüentes foram de organização de núcleos de agricultores sem terra e registraram inclusive uma ocupação, visando à conquista de terras para assentamentos de grupos organizados de agricultores com a participação direta de muitos agentes religiosos e diversas organizaçôes políticas, religiosas ou não governamentais, e durou de 1982 a 1984.

Para os agricultores que permaneceram em Nova Ronda Alta houve muitas tensões, uma vez que a definição incondicional do projeto proposto pela Igreja foi de que os agricultores que ali permanecessem estivessem de acordo com um trabalho cooperativo. Estabeleceu-se um período de muitas mobilizaçōes com pressões sucessivas, fazendo com que o Governodo Estado comprasseáreas e reassentasse os agricultores. Muitas dessas discussões envolveram impasses que podem ser avaliados pelo seguinte depoimento:

[...] teve muito problema, e aí se estabeleceu muitas normas, que quem falhasse tanto estava excluído do acampamento, alguns foram expulsos. Teve brigas. Eu lembro que quando foi na hora de distribuição das terras, quem ia para Conquistadora, quem ia para Vitória da União, ou quem ficava em 
Nova Ronda Alta, mas deu uma briga. O que tinha de gente com revolver e faca na cinta, eu tive que, uma vez, na celebração, logo depois de 30 de outubro, tive que fazer desarmar todo mundo numa celebração. Pedi que trouxesse sobre o altar, faca, revólver, porque estavam querendo se matar. Brigamos tanto tempo pela terra e agora estamos perdendo o juízo... Eu peguei a Bíblia e fiz coisa que nunca pensei em fazer na minha vida, tipo um pastor crente: "Em nome de Deus, eu apelo, eu peço, larguem seus revólveres e suas facas e tragam aqui." Deu um frio, um rolo, mas o pessoal trouxe e deu pra usar um pouco mais de calma. (Carter, 1994, p. 30-31).

O termo "Nova Ronda Alta - Terra Prometida”, em faixa esten dida na porteira de entrada do assentamento e inclusive transformada em música regional, foi de fato a consagração do peso da Igreja (Doimo, 1995, p. 141).

Demonstra-se assim o peso da instituição que, naquele momento, viabilizou as reivindicações e canalizou os esforços e o trabalho de alguns setores da Igreja que, isolados, dificilmente alcançariam algum sucesso.

\section{A ENCRUZILHADA NA FAZENDA ANONI}

Entre o acampamento da Encruzilhada Natalino (1981-1982) e a ocupação da fazenda Anoni, em outubro de 1985, no município de Sarandi, no Rio Grande do Sul, cresceu significativamente a organização do movimento dos agricultores sem-terra, em nível nacional. As formas de lutas centradas na questão da terra nos estados do Sul definiram, nos primeiros tempos, o roteiro e as características organizativas que, gradativamente, tornaram concreto o Movimento dos Trabalhadores Rurais Sem-Terra para a sociedade brasileira.

Sua organização inicial passava pela identificação de agricultores semterra nos municípios onde houvesse uma possibilidade de contato com a rede de agentes religiosos ou das entidades, que se envolveram com as lutas num destes estados. O MST vem a ser o resultado dessa rede e suas tensões no período em que ele se formou.

Do acampamento da Encruzilhada Natalino, aponta-se uma ação mais planejada, que procurou dar forma a parte de todo um complexo de or- 
ganizações e grupos envolvidos naquela luta. Os agentes da Pastoral da Terra no Rio Grande do Sul estão à frente desse processo que, no estado, resulta nos primeiros núcleos do Movimento dos Trabalhadores Rurais Sem-Terra (MST).

Em relação ao MST, a preocupação expressa politicamente era uma só: organizar esse segmento dos trabalhadores rurais. Para tanto, as discussões foram sistematizadas e são estas algumas das diretrizes estabelecidas pelos agentes de pastoral: organização dos regionais de sem-terra; levantamento de sem-terra nos regionais; reuniōes dos regionais; tarefas concretas do trabalho de base; reuniões nas comunidades; mobilizações; material didático; boletim Sem-Terra; encontros especiais; sugestôes.

Para se ter uma idéia da dimensão organizativa do trabalho da CPT nas comunidades, veja-se os tópicos do planejamento do trabalho sindical no município de Erval Grande, no Norte do Rio Grande do Sul, registrado em caderno de formação:

12 Passo: preparar lidera nças que quisessem assumir a próp ria caminhada.

2 ํ Passo: Estudo e "in tromissão" no trabalho do sindicato.

$3^{\circ}$ Passo: Roteiro nas comunidades para organização da Chapa.

$4^{\circ}$ Passo: Publicação do livreto:

* Por que surgiu a Chapa 2?

* As lutas que se tem pela frente.

* Que tipo de sindicato precisamos e queremos?

Essa é a forma característica dos roteiros de reflexão preparados por entidades ou grupos de pastorais que se espalharam entre o meio rural e nas periferias dos centros urbanos durante esse período. Com preocupações que giram em torno de uma perspectiva prática no desencadeamento do que designam de ações concretas, esses agentes desenvolveram distintas posturas, transitando entre a posição de direção política dos grupos onde estavam vinculados até a isenção absoluta em qualquer decisão que requeresse uma definição por parte da comunidade. 
A CPT terá os perfis dessa multiplicidade de posturas. A motivação individual do agente é apenas um dos aspectos que incidirão sobre o desenvolvimento de todas essas atividades. Ela encerra mais do que disposição individual. Traz a ambigüidade daquele que não se dissocia de sua representação:

Ao falarmos pois, em Igreja Popular, não podemos jamais desconsiderar o fato de que ela sempre esteve ancorada na institucionalidade da Igreja. Ora, se as CEB's se desenvolveram horizontalmenteno plano das relaçõesinformais, as linhas e diretrizes pastorais, ainda que agreguem bases ativas no processo de tomada de decisões, dependem da estrutura formal, verticalizada e hierarquizada da instituição. (Doimo, 1995, p. 141).

É com essa ambigüidade que os agentes de pastoral vinculados à CPT estabelecem relações com os segmentos da população rural que mais empobreceram no decorrer da década de 1970, e que, em parte, reproduzem na própria Igreja os formatos dos movimentos com os quais se envolvem e auxiliam na organização.

Os núcleos de agricultores, e aqui mais especificamente de agricultores sem terra, em muitas localidades acabavam articulados em torno de outras motivações, como grupos de Igreja, sejam CEB's, grupos de pastoral da terra ou pastoral rural. Assim, grupos com uma identidade religiosa e institucional, e que também se organizavam em torno da demanda de terra, identificando-se com o movimento, simplesmente desapareciam da localidade quando ocorria a ocupação de terra. Esse processo antecedeu, em muitos lugares, a ocupação da fazenda Anoni. ${ }^{10}$ A essa característica sobrepunha-se o momento no qual vivia a sociedade brasileira, quanto às mobilizações no meio rural. A mobilização era intensa:

${ }^{10}$ São dois os trabalhos que informam sobre esse episódio: Schimidt (1992) e Schwendler (1995). 
Durante o primeiro semestre de 1985, o MST esteve no centro dos acontecimentos relativos à promessa do governo federal de implementar um amplo programa de reforma agrária, conhecido como PNRA - Programa Nacional de Reforma Agrária [...] Como parte de seu elenco de pressóes em julho foi montado um acampamento "demonstrativo" da força do Movimento, quando 10 mil agricultores sem terra se reuniram durante três dias exigindo a rápida implantação do PNRA, entre outras demandas. Finalmente, em outubro de 1985 , 6. 500 pessoas, oriu ndas de aproximadamente 50 municípios, em operação cuidadosamente planejada e com resultados espantosos em termos de precisão e minúcia, ocuparam uma fazenda de nome Anoni, de área equivalente a 10 mil hectares. Esta propriedade havia sido oficialmentedesapropriada, em 1974, para assentar os agricultores desalojados pela construção da barragem do Passo Real [...], mas o proprietário vinha conseguindo protelar, através dos inúmeros recursos possibilitados pela justiça agrária brasileira, a desocupação da área. (Navarro, 1996, p. 94).

Essa mobilização está articulada ao processo de democratização da sociedade e, como apontado anteriormente, no caso das comunidades rurais e especificamente o agricultor sem-terra, pelo lançamento do I Plano Nacional de Reforma Agrária e pelo fato de a Igreja efetivamente orientar seu trabalho na perspectiva de viabilizar a sua realização.

A mudança do momento político no país repercutiu de forma muito profunda nas redes de organizaçôes dos movimentos populares, e a sucessão de demandas se estabelecia num ritmo muito acelerado, na conjuntura nacional. Praticamente nenhum setor em qualquer grau de organização popular deixou de se envolver nesses anos com as mobilizações que buscaram influenciar a Assembléia Nacional Constituinte (Doimo, 1995, p. 195). O crescimento notável das Organizações Não-Governamentais (ONG’s), ocupando boa parte do espaço anteriormente hegemonizado pela Igreja, também precisava ser levado em conta. (Doimo, 1995, p. 169).

Ainda no Rio Grande do Sul, entre o período do acampamento da Encruzilhada Natalino e o da fazenda Anoni, parte de indivíduos ou forças políticas coletivas aglutinadas em torno daquela primeira mobilização, no Comitê de Apoio ao Acampamento da Encruzilhada Natalino, deu origem 
a uma das mais expressivas ONG's no estado durante a década de 1980, que é o Centro de Assessoria Multiprofissional (CAMP). ${ }^{11}$

Dessa forma, seria outro o tecido das organizações que apoiariam os agricultores agora acampados na fazenda Anoni:

Estamos, em síntese, diante de diversas redes movimentalistas. Desde as locais, formadas por conjuntos específicos de pessoas que conectam diferentes grupos a partir de certa predisposição à participação e à organização de movimentos de ação-direta, até redes de maior abrangência das quais fazem parte as redes especializadas em diversosângulos da "luta popular" - análise e intermediação de projetos, recursos comunicacionais, produçãodo saber técnico-competente, memória ativa e solidariedade à distância, - a té redes territoriais, construídas nos contornos do ecumenismo secular e da chamada Igreja popular. (Doimo, 1995, p. 168).

Essa convergência de esforços caracterizava o período que precedeu a ocupação da fazenda Anoni. No contexto mais amplo viveu-se o processo de democratização da sociedade. Dentro dele acentuaram-se as lutas vinculadas à histórica bandeira da reforma agrária, em parte porque o próprio Estado lançou o Plano Nacional de Reforma Agrária, mobilizando os segmentosque nela pautaram suas estratégias de mobilização e de pretensóes políticas.

\footnotetext{
${ }^{11}$ Para se ter uma idéia desse significado, basta dizer que no CAMP sediavam-se os trabalhos de secretaria do Movimento dos Trabalhadores Rurais Sem-Terra (primeiro dos estados do Sul e, após 1985, com a mudança da secretaria nacional para São Paulo, permanece por mais algum tempo nele a secretaria estadual do movimento), a Secretaria da CRAB (Comissão Regional dos Atingidos Pelas Barragens do Rio Uruguai), até sua transferência para Erexim, e a secretaria da COSAU (Comissão Sindical do Alto Uruguai), que era uma frente de sindicalistas e oposiçôes sindicais à FETAG e que estruturou a parcela da base de sindicatos que formaram o Departamento Rural da Central Única dos Trabalhadores, todos eles com publicações próprias e demandas específicas. Tendo o autor participado de uma pequena parcela dessa experiência, cabe indicar que este espaço comum de trabalhos se constituía em um quotidiano de trabalho onde constantemente se entrecruzavam essas demandas, não raramente proporcionando um panorama abrangente a respeito das mobilizaçóes que envolviam os setores citados. Para maiores informaçōes, ver Armani (1989).
} 
Nesse campo de relações, que conforme apresentado é muito amplo, demonstra-se no espaço do acampamento da fazenda Anoni como se redefiniram as relações entre grupos religiosos e o MST no Rio Grande do Sul.

Embora situado num período de menor autoritarismo político do Estado, o acampamento da fazenda Anoni comparado ao acampamento da Encruzilhada Natalino guardava muitas similaridades. Em algumas delas, apontavam-se continuidades de relações, como no caso da presença de agentes religiosos em meio à organização dos agricultores. Situado fora dos domínios da paróquia Nossa Senhora dos Navegantes, de Ronda Alta, onde residia o padre Arnildo Fritzen, e sim na área de abrangência da paróquia do município de Sarandi, a organização do acampamento da fazenda Anoni contava na sua fase inicial com o apoio daquele pároco. Fatos simbólicos afirmavam essa continuidade.

Um deles foi o resgate da cruz do acampamento da Encruzilhada Natalino para dentro do acampamento da fazenda Anoni. Foi retirada do local onde os agricultores haviam deixado, quando saíram da Encruzilhada Natalino para o assentamento de Nova Ronda Alta.

A força simbólica dessa cruz continuou sustentada durante o acampamento da fazenda Anoni, uma vez que ela fora carregada um ano depois de formado o acampamento até Porto Alegre na Romaria Conquistadora da Terra. $^{12}$

Se em termos de articulação política a interferência dos agentes religiosos diminuiu consideravelmente de intensidade no acampamento da fazen da Anoni, ain da se construiu um espaço garantido qua nto às manifestações religiosas a fim de motivar os agricultores em muitos momentos nessa luta.

\footnotetext{
${ }^{12}$ A Romaria Conquistadora da Terra (1986) foi a maior mobilização externa do acampamento da fazenda Anoni e proporcionou o maior evento político em prol da reforma agrária no Estado do Rio Grande do Sul na década de 1980. Os dados aqui apresentados encontram-se referenciados em uma cronologia onde se apresenta essa trajetória, suprimida pelo autor neste artigo.
} 
Nesse período, estabeleceram-se outros espaços de onde se definem as decisões a respeito das lutas empreendidas pelo Movimento dos Trabalhadores Rurais Sem-Terra e, nessas esferas, a participação dos agentes religiosos são de outra ordem. Agentes pertencentes à coordenação estadual da CPT, por exemplo, quando participam desses momentos, o fazem na condição de convidados, e agentes religiosos mais locais, seja da CPT ou não, terão maior incidência nas decisóes do movimento, por estarem mais legitimados, uma vez que acompanharam os trabalhos de organização do acampamento e da própria estruturação do MST no estado.

Desse novo grupo de agentes, vale ressaltar os nomes do frei Sérgio Görgen, franciscano, que de fato acompanha os trabalhos de organização do MST, desde a sua função de coordenador de pastoral da Diocese de Frederico Westphalen, padre Otávio Klein, padre diocesano e assessor da pastoral da juventude da diocese de Passo Fundo, que está à frente, nesse período, da organização da Pastoral da Juventude Rural (PJR), o frei Wilson Dalagnol, ainda estudante de teologia da PUC, mas que via trabalhos de solidariedade dos estudantes de teologia com os agricultores sem terra, como voluntário em trabalhos específicos na secretaria estadual do MST, logo se define por integrar os trabalhos da CPT no estado, bem como o frei franciscano Vilso Antonelo. Os três últimos coordenam a CPT no Rio Grande do Sul a partir de 1987 até o início dos anos 1990.

A diferença das relações entre agentes com o MST, onde alguns deles, embora não compondo um grupo formalmente dirigente da CPT no estado, atuavam muito mais próximos das esferas de decisóes do movimento, na maioria dos casos a título de assessoria, traz implicações muito fortes seja na relação Igreja e MST, seja nas relações internas dos próprios agentes da CPT no Rio Grande do Sul.

Esta maior ou menor proximidade aos núcleos de decisão do MST se convertem imediatamente em maior adesão ou crítica às estratégias definidas pelo MST no estado. Com o aprofundamento de conflitos e o conseqüente aumento da violência,essa divisão polarizou-se ainda mais na segunda metade dos anos 1980. 
Ao lado disso, o acampamento da fazenda Anoni permitiu momentos de forte reafirmação da Igreja Católica, como quando o bispo de Passo Fundo, D. Urbano Algayer, realizou a crisma de quase 300 jovens e adultos em pleno acampamento. $\mathrm{Na}$ época do acampamento da Encruzilhada Natalino, D. Urbano respondera formalmente por toda a negociação, uma vez que era o secretário do Regional Sul III da CNBB. Sem resumir esse fato somente aos dividendos estratégicos que o MST certamente contabilizava com esse ato junto à Igreja do Rio Grande do Sul, revela-se com um sentido fortemente diferenciado de acontecimentos semelhantes ocorridos na Encruzilhada Natalino.

$\mathrm{Na}$ fazenda Anoni, Igreja e MST são institucionalmente duas forças autônomas, articuladas em função de interesses que podem ser comuns, mas resguardam-se os interesses específicos de cada segmento. De um lado, a Igreja está presente dentro do acampamento por intermédio de diversos agentes, defendendo inclusive posiçôes diferenciadas pelos motivos anteriormente explicitados mas mantendo os vínculos com os grupos de agricultores do acampamento, e, do outro, a direção do MST. As alianças, por situações bem determinadas, apresentavam composições reunindo sujeitos dos dois meios, e não era estranho haver discussões onde agentes religiosos posicionavam-se em lados opostos.

De outubro de 1985 a abril de 1996, quando então acontece a Romaria Conquistadora da Terra, ocorrem inúmeras pressōes do MST no Rio Grande do Sul reivindicando o assentamento das 1,5 mil famílias ali acampadas. A mais forte dessas mobilizações foi uma ocupação da sede regional do INCRA em fevereiro de 1996, cuja permanência dos agricultores forçou a vinda do secretário-geral do MIRAD, Simão Jatene, para negociar diretamente com os ocupantes.

Nesse período o movimento utiliza a ocupação das superintendências do INCRA como uma tática em muitos estados. Serão freqüentes a partir daí as ocupações de estabelecimentos públicos por parte desses agricultores em todo o Brasil. 
A negociação é demorada, e, na madrugada de 28 de fevereiro de 1986, os agricultores que se fizeram acompanhar de assessoria jurídica ${ }^{13}$ garantiram a assinatura de um documento do INCRA do Rio Grande do Sul, onde se estabeleciam prazos e metas em termos de agricultores assentados no estado. O prazo do acordo é o tempo onde se amadurece a estratégia da Romaria Conquistadora da Terra.

A Romaria Conquistadora da Terra nesse contexto ocupou um lugar significativo nos eventos que marcam a luta pela terra no estado e por ser o último momento forte onde a Igreja no Rio Grande do Sul aparece à frente de uma ação específica da luta pela terra.

$\mathrm{Na}$ condição de duas forças políticas que interagem permanentemente nesse cenário, a Igreja e o MST estabelecem uma estratégia de pressão na perspectiva de apressarem uma solução para o acampamento que, dado o seu tamanho, exigia contínuas formas de mobilizações para não sucumbir na desarticulação.

Depois das mobilizações pelas eleições diretas no estado, no ano de 1984, a chegada dos agricultores na capital será o ato político de maior afluência popular durante toda a década de 1980 e início dos anos 1990.

A romaria partiu da fazenda Anoni em 23 de maio de 1986, com previsão aproximada de um mês para chegar à capital. $\mathrm{O}$ roteiro, apesar de mais longo, com aproximadamente $500 \mathrm{~km}$ foi estrategicamente definido pela quantidade de cidades no seu percurso, que possibilitaria uma maior infra-estrutura durante a trajetória, bem como uma maior divulgação da questão. Noticiada pela imprensa, passou por cerca de 20 municípios de-

\footnotetext{
${ }^{13}$ Estavam presentes na negociação o Dr. Jácques Alfonsin, advogado de mérito largamente reconhecido entre os muitos movimentos sociais urbanos e rurais no Brasil, e que protagonizou alguns dos momentos decisivos de todas as negociaçóes aqui relatadas, e a irmã Sueli Belato, religiosa e advogada, que atuaram decisivamente na redação do documento. Através de relato, foi contado que por volta das $3 \mathrm{~h}$ da manhã, o superintendente do INCRA no Rio Grande do Sul e o secretário-executivo, já sem argumentos para apontar garantias de qualquer meta viável de desapropriação, aceitaram assinar o documento e, como tal, a responsabilidade perante as metas propostas.
} 
nunciando a necessidade de desapropriação de 32 mil hectares para o assentamento de 3,8 mil famílias, entre as quais as acampadas na fazenda Anoni. Foram 300 agricultores, incluindo mulheres e crianças acima de 10 anos. A primeira criança nascida na fazenda Anoni, Marcos Tiaraju, foi levada com sua mãe e em diversas comunidades foi apresentada como o primeiro bebê nascido no acampamento. ${ }^{14}$

A pressão se intensificou anteriormente, quando em $1^{\circ}$ de maio um grupo de famílias da Anoni acampou em frente ao INCRA, em Porto Alegre, com a disposição de sair somente com uma alternativa definida. A romaria significava um aumento da pressão, e durante todo o trajeto se estabeleceu um clima de surpresa frente ao seu desfecho quando da chegada na capital:

[...] contudo em Porto Alegre, não foi definido o que nem onde. "Tudo dependerá da conjuntura”, afirmam, mas deixam escapar a possibilidade de uma grande manifestação. Antes disso, terão pisado em 20 cidades: Passo Fundo, Marau, Casca, Nova Aracá, Nova Bassano, Nova Prata, Veranópolis, Bento Gonçalves, Farroupilha, Caxias do Sul, Nova Petrópolis, Dois Irmãos, Ivoti, Estância Velha, Novo Hamburgo, São Leopoldo, Sapucaia, Esteio e Canoas. (Zero Hora, 1986, p. 26).

\footnotetext{
${ }^{14}$ A sua mãe, de nome Rose, morreu em um protesto um ano depois, no trevo de Sarandi, quando um caminhão atropelou uma barreira de agricultores na estrada. Durante o período da caminhada e no período posterior realizaram-se filmagens no estado para um documentário a respeito da luta pela terra no Rio Grande do Sul, sob a direção de Tetê Morais. Com o acontecimento, o argumento do filme passa pela história de vida de Rose e das mulheres do acampamento, intitulando-se Terra para Rose. Posteriormente, com boa parte das imagens colhidas ainda inédita, a diretora volta em busca de muitos dos personagens desse primeiro documentário e grava um segundo, intitulado $O$ Sonho de Rose. A romaria está bem documentada nesse filme, com os momentos centrais aqui retomados. O nome Tiaraju, dado a seu filho é alusivo ao cacique Sepé Tiaraju, um dos símbolos da caminhada e mote simbólico das romarias da terra no estado.
} 
Durante todo o percurso, a imprensa publicou quase que diariamente a trajetória e ao mesmo tempo as repercussões no estado e nas negociações, pois essas rapidamente se estabeleceram com interlocutores bem-definidos: os agricultores na capital se articulavam com inúmeras entidades de apoio no Comitê Gaúcho Pela Reforma Agrária, a exemplo de Natalino, onde havia o Comitê de Apoio aos Agricultores Acampados na Encruzilhada Natalino, e sua ação na capital estava diretamente vinculada ao trabalho dessas entidades, embora, diferenciadamente do experiência anterior, o comitê pouco influenciava nas decisões, pois estas já vinham definidas das instâncias internas do MST, juntamente com a Coordenação do Acampamento da fazenda Anoni.

A Romaria Conquistadora da Terra fez repercutir para fora do estado o problema do acampamento e das negociaçôes. Na estratégia dos agricultores a proximidade com a capital aumentaria as chances de uma solução para o acampamento. No dia da chegada em Porto Alegre, em 23 de junho de 1986, reproduziu-se um folheto cujo verso trazia na íntegra o texto do acordo firmado em fevereiro.

Sob uma grande afluência popular que envolveu entrega da chave da cidade aos agricultores pelo prefeito Alceu Collares, ato público e ecumênico na praça da Matriz, a negociação acabou por instalar os romeiros no interior do prédio da Assembléia Legislativa, a fim de que sua permanência fosse viabilizada na capital.

O período que se seguiu foi predominantemente de pressões e desgastes na negociação, que resulta na saída dos agricultores sem terra dos recintos da Assembléia Legislativa quase 60 dias depois, havendo durante esse período o deslocamento do acampamento para o auditório, ao qual os próprios agricultores, no período de maior desgaste, referiam-se como uma "grande arapuca".

O tempo passado em Porto Alegre teve um início de grande atividade, com saídas dos agricultores para palestras em escola, paróquias, vilas, e demais grupos interessados e mobilizados. A população também se mobilizava para garantir alimentos e roupas, pois foi significativo o apoio anônimo, individual, de moradores sensíveis aos agricultores que acorriam ao auditório com essas doações. 
O sentido de arapuca pode ser remetido ao próprio sentimento que perpassava as lideranças do movimento, que, depois de algum tempo, buscava uma saída dita honrosa para os agricultores que, sem alternativas a curto prazo, continuavam acampados no interior da Assembléia Legislativa. A eles se juntavam nas negociaçôes as famílias, que desde antes da romaria já estavam acampadas junto ao INCRA e que ainda permaneciam lá.

A saída dos agricultores da cidade e o seu retorno para o acampamento dá início a uma nova trajetória à luta pela terra, no que diz respeito ao seu sujeito principal, o Movimento dos Trabalhadores Rurais Sem-Terra no Rio Grande do Sul.

Nos anos que seguem ocorremconfrontos significativos, principalmente entre agricultores sem terra e contingentes de policiais militares, num visível processo de radicalização em torno da luta pela terra.

\section{A RADICALIZAÇÃO DA LUTA PELA TERRA E A POSIÇÃO DA CPT}

O contexto de ampliação das lutas funciona como uma rápida ascensão do MST na abrangência territorial de suas lutas no estado:

[...] em 1987, durante o primeiro Seminário Estadual dos Sem Terra, se decidiu que o "problema da Anoni é um, e o problema dos sem terra é outro", o que indicava que o MST não pretendiamanter-se mais preso pela indefinição que caracterizava o acampamento da Anoni e pretendia, a partir daí, implementar um outro ciclo de ocupaçôes, o que efetivamente foi feito. Realizaram uma ocupação durante o primeiro semestre e, em julho, ocuparam uma outra fazenda, a São Juvenal, na região central do estado, o que representaria uma sensível mudança na natureza das ocupaçôes, a partir daí. Isto porque os agricultores foram despejados da fazenda com grande violência e, principalmente, porque o despejo não foi sequer mediado pela Brigada Militar, como geralmente ocorrera em outros casos, mas foram expulsos diretamente por um contingente de 400 fazendeiros da região. Tal fato gerou um sentimento de frustração, mas também redirecionou a ação dos colonos sem-terra em direção a uma maior radicalização. (Navarro, 1996, p. 95). 
Depois do confronto na fazenda São Juvenal, ainda constam dois conflitos muito importantes para completar este ciclo, bem como investigar com mais propriedade o novo formato de participação dos agentes religiosos.

O primeiro deles foi a ocupação da fazenda Santa Elmira, em Salto do Jacuí, ${ }^{15}$ onde cerca de 500 agricultores enfrentam um contingente de cerca de 1,2 mil policiais e, segundo a narrativa de Görgen (1989), contingentes de forças paramilitares de fazendeiros da região. Mesmo relativizada a narrativa desse conflito, o grau de violência atingida não conta com precedente na história dos conflitos rurais no estado.

Com pouco mais de um ano de distância, em 8 de agosto de 1990, 400 agricultores desembarcam diretamente de ônibus na praça da Matriz, a fim de instalarem acampamento e protestarem a respeito de promessas de assentamento não cumpridas. Inexplicavelmente, o aparato oficial de segurança do Estado não conseguiu prever tal situação e evitá-la. Repetem-se situações semelhantes ao conflito da fazenda Santa Elmira. Durante ainda negociações no palácio do governo, em comissão que envolvia parlamentares, secretário de segurança e agricultores, o comando da polícia de choque entra em ação para dispersar os agricultores da praça, que apresentaram alguma resistênđa com pedras e ferramentas de produção que levaram para protestar.

A perseguição aos agricultores espalhou-se pela cidade:

A confusão foi geral. Ninguém esperava por isto. Os colonos atacados descem para o centro da praça e tentam se defendercom seus instrumentos de trabalho.

\footnotetext{
${ }^{15}$ Este conflito está minuciosamente relatado a partir da ótica do frei Sérgio Görgen, franciscano, atualmente deputado estadual eleito pelo PT, membro da CPT e ativo assessor do MST até hoje, e que, na época, se junta a eles antes do confronto. O livro $O$ Massacre da Fazenda Santa Elmira (Görgen, 1989) é quase um diário, rico em informaçôes, e tem uma peculiaridade: nominalmente vai apontando a trajetória pela qual decisões são e deixam de ser tomadas ou executadas em momentos como esse. No final, a história se repete: não se sabe a origem da ordem. Esse roteiro de deliberada falta de responsabilidade nas ações militares durante esse período faz-se sentir novamente um ano depois, no conflito da praça da Matriz, em Porto Alegre.
} 
São atacados a tiros. Vários caem feridos. Os demais fogem. A Brigada os persegue pelo centro da cidade, Nesta correria, um soldado, com uma arma em punho, tenta deter os colonos que fogem. Dá-se novo entrevero. Os colonos estavam desesperados. O soldado está sozinho e também se desespera, dando dois tiros ao chão e um terceiro que atinge o estômago de uma agricultora. O soldado é ferido mortalmente. Os agricultores continuam fugindo e se refugiam na Prefeitura Municipal, que passa a ser cercada pela Brigada Militar. Saem somente à noite, após solução negociada para serem ouvidos pela Polícia Civil. (Comissão Pastoral da Terra, 1990). ${ }^{16}$

Entre um conflito e outro, em junho de 1990, o agricultor Ivo Lima, de 19 anos, é baleado com um tiro que lhe atravessa o cérebro, quando do encontro de uma passeata de agricultores que se dirigiam da cidade de Cruz Alta para o acampamento próximo, sendo interpelados por um grupo de policias militaresque estavam em guarda em local próximo do caminho. Este agricultor acabou com lesão irreversível que lhe tirou parte dos movimentos.

Tomando como referência esse período da luta pela terra e a intensidade dos confrontos, é possível compreender as reservas de autoridades eclesiáticas que, embora nunca negando uma palavra firme diante de todas essas tensões em favor da luta pela terra e de agricultores acampados, dividem-se agora quanto ao apoio incondicional a essas lutas. Essa posição, própria de uma instituição como a Igreja Católica, será vista com reserva por muitos dos agentes pastorais envolvidos com o MST, até mesmo facilitando o poder do discurso político de alguns deles, que se projetam então em cenários políticos extra-eclesiais.

\footnotetext{
${ }^{16}$ A exemplo da fazenda Santa Elmira, Görgen coordena a publicação do livro Uma Foice Longe da Terra (1991), que além da narrativa desse conflito, traz artigos que auxiliam a compreensão da conjuntura da luta pela terra no momento. Recomenda-se também a leitura da obra Quem faz Gemer a Terra (Kiefer, 1991), pequeno romance que conta a vida do agricultor que desferiu o golpe que acabou por matar o soldado Valdeci Abreu Lopes, que fazia policiamento regular no centro da cidade e foi surpreendido com o tumulto. As versões do episódio são várias e quatro agricultores continuam presos como responsáveis pela morte do soldado.
} 


\section{SOCIEDADE DEMOCRÁTICA E DESAFIOS PARA A AÇÃO PASTORAL}

A seqüência destes conflitos coloca os agentes que ainda permaneciam na CPT em uma situação de ambigüidade, pois agora Igreja e movimentos sociais no Rio Grande do Sul constituem-se em interlocutores muito distintos. A seqüência de seu trabalho passa a requerer um discernimento maior destas relações e uma contabilidade nem sempre fácil de fazer, saturada por definições ideológicas, como a idéia de escolhas que se pautem por uma suposta fidelidade ao povo e a ordem institucional da Igreja.

Apontam-se aspectos que desafiam o caráter da continuidade da CPT e que se mesclam com as próprias mudanças que a sociedade como um todo enfrenta. Colocam-se situações contraditórias para a CPT, uma vez que sua mediação está tensionada pela ambiguidade das suas relações com a Igreja e com os movimentos sociais no campo.

O primeiro é o propósito de formação de consciência entre os grupos populares, que a CPT assume como tarefa, sob uma multiplicidade de recursos e definições ideológicas. A sua opção institucional lhe apresenta uma contradição, pois a mantém afastada de um perfil mais definido em torno de uma opção ideológica, apesar de seus agentes tomarem posições abertas nesse sentido. Há também a necessidade de converter toda a leitura em um discurso religiosoem nome do reconhecimento eclesial. Assumirá assim cada vez mais o roteiro de reflexão proposto pela Igreja Católica para orientar o trabalho de seus agentes, visando uma maior legitimidade de sua ação pastoral. Esse formato não incorpora muito das discussões internas dos movimentos sociais, e estabelece-se assim uma defasagem dos agentes frente à pauta de discussões dos movimentos sociais. Um outro efeito é que ela se distancia significativamente do que era atrativo na sua condição do período analisado, que era o reconhecimento como uma rede de inserção de agentes nas lutas sociais em pauta no campo. A Igreja também diversifica a sua orientação e a diminuição de agentes com essas disposiçôes também é evidenciada.

O segundo diz respeito à formação de novos valores como perspectiva de mudança global. Cresceu muito na década de 1990 a possibilidade da 
religião constituir-se como força que mobilize a sociedade na direção de valores que resgatem a condição do homem como ser integrado à natureza e aos seus pares. Nesse sentido, é muito forte o apelo às organizações e grupos identificados com o tecido dos movimentos sociais que estabeleçam parâmetros dessa reflexão e concentrem aí seus esforços de sistematização e troca de experiências.

O espaço institucional da Igreja demora para incorporar de forma mais ampla essas modificações, e a CPT em particular com essa lentidão, uma vez que o distanciamento da Igreja lhe imporia ainda uma condição mais frágil. Assim, o seu reconhecimento como agente central nas lutas sociais acaba se deslocando para uma condição mais suplementar.

Decorrente dessa questão, há um terceiro aspecto que incide sobre um de seus princípios, que é a denúncia dos mecanismos de exploração no meio rural no Brasil. Ela deteve, pelo menos nos últimos 30 anos, o monopólio da voz dessas denúncias no âmbito eclesial. As situaçôes de exploração ainda não estão superadas e a CPT continuará se pautando por uma condição de denunciar o que no seu entendimento se constitui em uma situação de injustiça e desagregação social. Se a tradição de denúncias em torno dos conflitos no campo marcaram a CPT, e mesmo que incorpore novas situações como o trabalho escravo e do trabalho infantil na agricultura, essas dimensões só têm significado se articuladas às organizações da sociedade que pautam as suas açõ es pelos mes mos referenciais. O distanciamento dos agentes da CPT do quotidiano das mesmas relativizaria a força de suas denúncias.

Em quarto lugar, observa-se a dimensão do poder político como poder local. Articulada a outros segmentos que compóem a chamada pastoral social da Igreja Católica, a CPT estimulou o aprofundamento da participação política dos agricultores, com base na compreensão de que esta participação consolida as experiências dos movimentos sociais e aprimora o agente na sua compreensão política, quando dela participa. Esse aspecto exige o aprimoramento de forma contínua e a qualificação tanto dos agentes da CPT quanto dos seus interlocutores, uma vez que muitos estão em posiçôes referenciais, isto é, são ouvidos nos grupos de base com mais atenção. 
A estrutura da CPT deve dar conta então dessa qualificação, e nem sempre conta com os recursos necessários para se viabilizá-la de forma satisfatória.

Tendo por base a complexidade da formação do indivíduo na sociedade, a ação pastoral de organismos como a Comissão Pastoral da Terra necessitaria de uma densidade na sua reflexão que às vezes contrasta com as dificuldades de reprodução que ela apresenta.

Está colocada para a CPT a necessidade de compreender melhor a multiplicidade de esferas de leituras da realidade e dos elementos que hoje influenciam a formação do indivíduo. Numa sociedade onde esses recursos são cada vez mais escassos, a condição de haver a CPT em uma determinada localidade pode significar a possibilidade de que por ela passem outras experiências de formação da cidadania e que, pelo formato próprio dessas atividades pastorais, se estabeleçam possibilidades de trocas de visão a respeito da condição do indivíduo que protagoniza essa experiência. Para tal desafio e nos limites atuais da ação da Igreja na esfera política, a CPT requer uma adequação que clama de uma maneira mais intensa que a sua capacidade de resposta.

\section{REFERENNCIAS}

ARMANI, Domingos. Centros de educação e promoção popular, classes populares e hegemonia: a trajetória do CAMP. Dissertação (Mestrado em Ciência Política)- Prog rama de Pós-Graduação em Ciên cia Política, Instituto de Filosofia e Ciências Humanas, Universidade Federal do Rio Grande do Sul, Porto Alegre, 1991. $491 \mathrm{f}$.

CARTER,Miguel. EntrevistaPe. Arnildo Fritzen. Porto Alegre: Acervo CPT, 1994. Mimeografado.

COMISSÃO PASTORAL DA TERRA. Posicionamento da CPT-RS frente aos conflitos pela terra no Rio Grande do Sul. Porto Alegre, 1990. 
COSTELLA, Maria. Igreja e luta pela terra no Rio Grandedo Sul: organização e poder. Dissertação (Mestrado em Sociologia)-Programa de Pós-Graduação em Sociologia, Instituto de Filosofia e Ciências Humanas, Universidade Federal do Rio Grande do Sul, Porto Alegre, 1992. 210 f.

DOIMO, Ana Maria. Os rumos dos movimentos sociais nos caminhos da religiosidade. In: KRISCHKE Paulo; MAINWARING, Scott. A Igreja nas bases em tempo de transição: (1974-1985). Porto Alegre: L\&PM: CEDEC, 1986. p. 101-130.

. A vez e a voz do popular. movimentos sociais e participação política no Brasil Pós-70. Rio de Janeiro: Relume-Dumará: ANPOCS, 1995. 353 p.

ECKERT, Córdula. Movimento dos Agricultores Sem Terra no Rio Grande do Sul: 1960-1964. Dissertação (Mestrado em Ciência de Desenvolvimento Agrícola)-Instituto de Ciências Humanas e Sociais, Universidade Federal Rural do Rio de Janeiro, Itaguaí, 1984.

GAIGER, Luís Inácio Germany. Agentes religiosos e camponeses sem terra no Sul do Brasil: quadro de interpretação sociológica. Petrópolis: Vozes, 1987.

GEHLEN, Ivaldo. Uma estratégia camponesa da conquista da terra e o Estado: o caso da fazen da Sarandi. Dissertação (Mestrado em Sociologia)-Prog rama de Pós-Graduaçáo em Sociologia,Instituto de Filosofiae Ciências Humanas, Universidade Federal do Rio Grande do Sul, Porto Alegre, 1983. 221 p.

GÖRGEN, Sérgio A. O massacre da fazenda Santa Elmira. Petrópolis: Vozes, 1989. 147 p.

KIEFER, Charles. Quem faz gemer a terra. Porto Alegre: Mercado Aberto, 1991. $114 \mathrm{p}$.

MARCON Telmo. Acampamento Natalino: encruzilhada de contradiçóes. Dissertação (Mestrado em História)-Programa de Pós-Graduação em História, Universidade de Brasília, Brasília, Distrito Federal, 1989. 240 f. 
MARTINS, José de Souza. Os camponeses e a política no Brasil: as lutas sociais no campo e o seu lugar no processo político. Petrópolis: Vozes, 1981

A militarização da questão agrária no Brasil: terra e poder: o problema da terra na crise política. Petrópolis: Vozes, 1984. 134 p.

NAVARRO, Zander (Org.). Politica, protesto e cidadania no campo: as lutas sociais dos colonos e trabalhadores rurais no Rio Grande do Sul. Porto Alegre: Ed. da UFRGS, 1996. 228 p.

REVISTA RENOVAÇÃO. Porto Alegre, n. 148, p. 2-3, 1981.

. Porto Alegre, n. 154, p. 12-15, 1982.

. Porto Alegre, n. 159, p. 19-28, 1982.

SCHERER, Vicente. Terras da Igreja. Revista Renovação, Porto Alegre, n. 150, p. 2-3, 1981.

SCHIMIDT, Cláudia Job. O tempo de acampamento: a construção da identidade social e política do "colono sem-terra". Disser tação (Mestrado em Sociologia)-Programa de Pós-Graduaçáo em Sociologia, Instituto de Filosofia e Ciências Humanas, Universidade Federal do Rio Grande do Sul, Porto Alegre, 1992. 2 v.

SCHIO, João Bosco. Depoimento. In: PAIVA, Vanilda. Igreja e questão agrária. São Paulo: Loyola, 1985. p. 52-67.

SCHWENDLER, Sônia Fátima. Da utopia do acampamento à recriação social do assentamento Dissertação (Mestrado em Extensão Rural)-PósGraduação em Extensão Rural, Universidade Federal de Santa Maria, Santa Maria, 1995. $144 \mathrm{f}$.

ZERO HORA. Porto Alegre, p. 25-26, 24 maio 1986. 